\title{
Empathy and Psychiatric Illness
}

\section{Matthew Ratcliffe}

\section{Introduction}

It has become something of a commonplace for philosophers to observe that the term 'empathy' has been and continues to be used in a number of different ways (e.g. Coplan, 2011, p.40; Zahavi, 2014, p.152). I accept that this is the case, although I am less sure that it should be. Nevertheless, given the possibility that 'empathy' legitimately refers to a range of different cognitive achievements, I will restrict my enquiry here to something that people often (but by no means always) refer to as empathy in the context of psychiatric illness. I will sketch an account of what it is to empathize with experiences of psychiatric illness by asking 'what, exactly, is lacking or judged to be lacking when the sufferer states that others do not or cannot empathize with her?' and, conversely, 'when she does feel empathized with, what is it that she recognizes?' The answer to these questions, I will suggest, points to a conception of empathy that differs markedly from the kinds of cognitive achievement philosophers tend to associate with the term.

Most recent philosophical accounts of empathy appeal to one or another form of mental simulation. Empathy is said to consist, partly or wholly, of person A's generating a first-person experience that is similar to person B's experience, in order to understand the latter. Proponents of the view tend to distinguish two types of simulation: an explicit, effortful modelling of somebody else's experience, and an implicit replication process that facilitates a perceptual or at least perception-like appreciation of experience. For instance, Goldman (2011, pp.33-6) describes both "reconstructive" empathy and automatic "mirroring" (see also Goldman, 2006; Stueber, 2006). A further distinction has been drawn between two types of explicit simulation. One might think of simulation in terms of putting oneself in another person's physical or psychological situation and then imagining what one would experience, think, or do. However, it has been argued that this is insufficient for empathy: one has to somehow occupy the other person's perspective, rather than attempt to model what he experiences while retaining one's own first-person perspective. Hence Gordon (1995, p.734) appeals to an ability to "recenter" one's “egocentric map", while Darwall (1998, p.268) maintains that "projective empathy" 
involves feeling "as though we were they", and Coplan (2011, p.53) similarly insists that empathy involves "other-oriented", rather than "self-oriented" perspective-taking.

I will show how empathizing with experiences of psychiatric illness often involves something importantly different from both kinds of explicit simulation. It is not so much a matter of generating similarities, as recognizing the possibility of profound forms of phenomenological difference that people are more usually oblivious to. Indeed, when acknowledgment of difference by A is successfully conveyed to B, this sometimes suffices for B's recognition of empathy on the part of A. Furthermore, understanding someone else's experience by means of simulation is psychologically impossible in at least some cases. Insofar as empathy is still achievable in these cases, it must therefore be something else.

Empathy is generally taken to involve more than just understanding; one must also experience something of what another person experiences. And this, one might worry, is something that an emphasis on difference-recognition does not capture. So there may still be a role for implicit simulation mechanisms, which facilitate a perceptual or quasi-perceptual appreciation of at least some aspects of the other person's experience. However, I will distinguish three ways in which one might be said to 'experience someone else's experience', at least two of which are not principally a matter of simulation. These two, I will suggest, play a more central role in the kind of empathy described here. In so doing, I will also distinguish my account of empathy from an approach that originates in the phenomenological tradition of philosophy and is often pitted against simulation theory. According to that approach, empathy is a distinctive kind of intentionality, which enables a perceptual or perception-like appreciation of another person's experience (e.g. Stein, 1817/1989; Zahavi, 2007, 2011, 2014, Thompson, 2007). Even though this kind of appreciation has some role to play, it is just one part of a larger picture.

Hence I will arrive at a distinctive conception of empathy, one that may also have wider applicability. It does not conform to any simulationist approach to empathy, and neither is it to be identified with the 'phenomenological' alternative. It is, however, quite consistent with many descriptions of empathy that have been offered by clinicians, in psychiatric contexts and more 
widely, and could be pieced together from their various remarks (e.g. Halpern, 2001, 2003; Havens, 1986; Margulies, 1989).

\section{Disturbances of Empathy}

The theme of feeling estranged from other people in general features in many first-person accounts of psychiatric illness, and is not specific to any particular diagnosis. J. H. van den Berg (1972, p.105), in a phenomenological characterization of what he calls the 'typical psychiatric patient', describes this as follows:

The psychiatric patient is alone. He has few relationships or perhaps no relationships at all. He lives in isolation. He feels lonely. He may dread an interview with another person. At times, a conversation with him is impossible. He is somewhat strange; sometimes he is enigmatic and he may, on rare occasions, be even unfathomable. The variations are endless, but the essence is always the same. The psychiatric patient stands apart from the rest of the world.

Experiences of interpersonal and social isolation are no doubt heterogeneous, and I do not wish to make sweeping generalizations concerning the kinds of experience associated with a specific psychiatric diagnosis or with psychiatric diagnoses in general. Nevertheless, it is safe to say that feeling cut-off from other people is a frequent and prominent aspect of psychiatric illness experience, even though the details of the experience may vary considerably. If we start by construing empathy in a fairly permissive way, as a matter of understanding what others experience, it is clear that actual and perceived failures of empathy are a central theme in the testimonies of many psychiatric patients. Other people either are, or at least appear to be, incapable of understanding what the person is going through - they seem unsympathetic, distant, and even hostile towards him. For instance, the claim that others do not or cannot understand what one is going through features consistently in first-person accounts of depression:

“....they are all selfish and don't understand"; “they don't understand and so act like nothing is wrong"; "It feels like no one else has ever experienced anything like this before, like you're all on your own"; "I find other people irritating when depressed, especially those that have never suffered with depression, and find the 'advice' often given by these is unempathetic and ridiculous"; "nobody understands or loves me"; "However much they say they understand, I don't believe 
them"; "There is the realization that you have never connected with anybody, truly, in your life"; "everyone seems so annoyingly normal, happy, able to cope, unaware of the turmoil that is filling my room, my head, my life, my world"; "You feel alone and in a world that cannot be easily explained or described."

On the other hand, the patient may knowingly or unknowingly fail to engage with the perspectives of others. Many of those who reflect back on their experiences of depression remark on their own failure to appreciate and engage with the perspectives of others, as well as their tendency to misinterpret other people in general as indifferent, disapproving, or hostile:

“....when I am depressed very small things annoy me. I get angry with my partner and children for any reason, yet really they are being themselves. I also find it hard to show kindness and emotion to them"; "when I start to get depressed, I only filter through the negative messages from friends and family, so even the most benign comment can be perceived as an insult"; "They seem distant, inaccessible, critical, hostile. I find it much harder to understand their points of view and they seem to struggle to understand mine."

Depression can involve a kind of self-absorption, a pre-occupation with one's own predicament. Thoughts about other people are often principally concerned with one's own suffering. Others fail to understand, regard one as worthless, or harbor hostile intentions: "When I am depressed I interpret many of the things that my family and friends do and say as being negative and most of the time persecutory. It is like everything they do is about me". (These testimonies were obtained via a 2011 questionnaire study on depression experiences, which I conducted with colleagues as part of the AHRC- and DFG-funded project 'Emotional Experience in Depression: a Philosophical Study. For further details, see Ratcliffe, 2015, Chapter 1.) In some cases, others are described not as specific individuals with distinctive emotions and concerns but in terms of an undifferentiated 'they', whose sole role in the depression narrative is to convey disapproval of the author (Ratcliffe, 2015, p.227). An extreme privation of interpersonal experience, more often associated with schizophrenia diagnoses, involves others not only starting to lose their distinctiveness as individuals but ceasing to be recognized as subjects of experience at all. They become "phantoms", or generic judges and persecutors that are bereft of other psychological characteristics (Minkowski, 1933/1970, p.329). Hence, despite the diversity of experience 
encompassed by the label 'psychiatric illness', and also by more specific diagnostic categories such as 'major depression' and 'schizophrenia', the actual and/or perceived lack of empathy by one or both parties is a conspicuous and wide-ranging theme. But what exactly is it that is lacking or perceived to be lacking?

\section{Recognition of Difference}

Perhaps, one might suggest, lack of empathy in the context of psychiatric illness is best accounted for in terms of one or another form of mental simulation: we ordinarily come to understand others' experience by replicating them in the first person, a process that is more likely to fail in challenging cases such as these. It is not entirely clear how the relationship between empathy and simulation (of whatever kind) is supposed to be understood. Assertions to the effect that simulation is empathy, simulation is necessary for empathy, empathy is partly constituted by simulation, or empathy somehow depends upon simulation processes could be construed as debatable -and perhaps empirically testable- claims concerning the relationship between two independently identifiable accomplishments, $x$ and $y$. Then again, it sometimes appears that the two are being treated as synonyms, rendering the claim that 'empathy' is 'simulation' true by definition. For example, Stueber (2006, pp.3-4) labels the view that simulation is our primary means of accessing other minds as the "empathy view". Whichever the case, one of the philosophical lessons we can learn by considering psychiatric illness is that empathy does not have to be construed as wholly or principally a matter of simulation, or even as necessarily involving simulation.

It could well be that, in severe depression for instance, a sufferer's ability to simulate the minds of those who are not depressed is limited, and vice versa. But this is not usually what is at stake when it is stated that others do not or cannot understand what the person is going through. In some such cases, it could be that others do in fact understand but are misinterpreted as incapable or indifferent. Nevertheless, I think there is some truth to remarks that feature frequently in firstperson accounts of psychiatric illness, to the effect that others do not or cannot comprehend the experience, or at least central aspects of it. Experiences of severe psychiatric illness are often described in terms of inhabiting a radically different world, an isolated, alien realm that is set 
apart from the consensus reality taken for granted by others as an unwavering backdrop to their experiences, thoughts and activities:

When people suggested to me that I had no good reason for being so full of self-disgust, their words made no sense. I was torpid, a sham, and deserved no self-respect. Most of all I was terribly alone, lost, in a harsh and far-away place, a horrible terrain reserved for me alone. There was nowhere to go, nothing to see, no panorama. Though this landscape surrounded me, vast and amorphous, I couldn't escape the awful confines of my leaden body and downcast eye. I didn't want to live, but I couldn't bear to die. (Shaw, 1997, p.40)

Sufferers describe a global change in the structure of their experience. As the author of a wellknown autobiography of schizophrenia puts it, madness is a "country" that is "opposed to reality" (Sechehaye, ed. 1970, p.44). What is altered or lost is a sense of being comfortably immersed in a shared world, something that is so deep-rooted for many of us that it does not become an object of explicit reflection or enquiry. However, one does come to explicitly contemplate this aspect of experience when it is diminished or distorted. And, in seeking to describe it, one faces the challenge of conveying a change in $x$ to those who have not yet recognized the existence of $x$ :

You know that you have lost life itself. You've lost a habitable earth. You've lost the invitation to live that the universe extends to us at every moment. You've lost something that people don't even know is. That's why it's so hard to explain. (Quoted by Hornstein, 2009, p.213)

To comprehend such experiences, it must first be recognized that something we more usually take for granted is susceptible to disturbance, that radical phenomenological difference is possible. This recognition of potential difference is quite different from the task of attempting to bridge already established differences by means of simulation. Of course, some phenomenological differences are effortlessly and routinely recognized, and so it might be objected that recognition alone is not much of an achievement at all. For example, suppose that I am sitting at a table with person B, looking at a glass of wine. I recognize that B's position in the room gives her a perspective on the glass that differs from my own. I also recognize that the glass does not look inviting to B in the way it does to me, as B has just told me she does not like 
the taste of wine. Whenever I interact with another person, I register any number of phenomenological differences, some or all of which could conceivably be bridged by means of simulation. However, at the same time, I continue to take it as given that we inhabit the same social space, where chairs are for sitting on, tables are for placing drinks on, bars are for ordering drinks from, it is appropriate to talk informally, it is not appropriate to throw glasses against the wall, and so forth. In other words, one does not have to project, wholesale, an appreciation of norms, roles, artefact functions, and so forth onto the other person. It is something that both parties presuppose in the guise of a shared situation: it is 'ours', rather than 'mine' and also 'yours'. Much of what we experience is like this; it is not differentiated into yours and mine, but accepted as our world. I think this is partly what Jaspers (1912/1968, p.1315) seeks to convey with the following passage:

We understand other people, not through considering and analysing their mental life, but by living with them in the context of events, actions and personal destinies. Even when we do on occasion give consideration to mental experience as such, we do this only in a context of causes and effects as understood by us, or else we make a practice of classifying personalities into categories, etc.

Where potential or actual differences between A and B are more radical, where the 'world' is not shared to such an extent, the task of understanding requires us to suspend assumptions of commonality. And there is more to this suspension than just recognizing that person B may not share a common, habitual, unthinking appreciation of norms, roles and functions, which more usually appear as integral to the experienced world. B may have lost the sense that things could ever be different in a meaningful way, the sense of being spatially and temporally situated in a shared world, the sense that reality is separate from her imaginings (Ratcliffe, 2012). The task of understanding may be further obfuscated by B's sense of irrevocable estrangement from others, which may involve indifference to A's attempts to communicate or hostility towards A.

Hence acknowledging the possibility of profound phenomenological difference is essential to empathy in this context. This theme is all but absent from simulationist accounts, and also from phenomenologically inspired alternatives that emphasize some form of perceptual or quasiperceptual relation. However, the need for heightened 'openness' is a consistent theme 
throughout the clinical literature on empathy. For example, Halpern (2011, xi-xii) states that "genuine curiosity and openness to learning something new" is the "most important pathway to empathy" in clinical settings, and Margulies (1989, p.12) remarks that empathy involves "the capacity to go against the grain of needing to know". Havens (1986, pp.16-21) talks of "finding the other", something that involves entering "that person's world". One might think of "entering" in terms of duplicating the other person's experiential world, but what Havens actually emphasizes is the recognition and exploration of phenomenological difference: the "empathic visitor discovers what he has taken for granted in his own world: that it is a world of particular time and space". This kind of interpersonal openness is arguably not just an aspect of empathy but itself sufficient for a kind of empathy: when A is recognized by B as adopting such an attitude towards her, A is recognized as empathic. For instance, Sass and Pienkos (2012, p.32) stress how empathy involves "recognizing what is otherwise in persons with psychosis", and observe how "patients can feel quite moved in being asked about these experiences". Havens (1986, p.24) also describes how clients can "light up in recognition of your sudden presence in their lives", something that involves a sense of being "found".

This poses a further problem for accounts of empathy that emphasize B's replicating A's experience. A's all-enveloping sense of interpersonal isolation is to some extent mitigated by recognition of empathy on the part of B. So empathy, at least where there is a sense of mutual recognition, does not just involve understanding a pre-formed experience; the act of successfully empathizing with an experience can itself change the nature of that experience. This is especially so when the initial experience involves a sense of isolation from everybody, a pervasive lack of interpersonal connection. So the object of empathy is a moving target, not something episodic or constant that one holds in suspension and duplicates. As Havens (1986) further remarks, an initial experience of mutual recognition can serve as the starting point for a variably collaborative process, whereby the nature of interpersonal difference is progressively clarified and a more positive understanding of experience assembled. No doubt, this could involve various acts of imagination on the part of the empathizer, some of which will meet the criteria for one or another type of simulation. However, more central is an acknowledgement of the other person's predicament as something that falls outside what many of us take as given. This 
acknowledgement involves a kind of openness to the distinctive perspective of a particular person, which resists the temptation to typify her or impose one's own perspective upon her.

\section{The Limits of Simulation}

So far, I have suggested that empathic openness does not centrally involve simulation, but there are also grounds for believing that the kinds of experience I have described could not be understood in such a way. As well as replicating circumscribed experiences and thoughts, one would have to replicate a much wider-ranging sense of belonging to the world. And it is arguable that wholesale replication of a 'phenomenological world' is psychologically impossible. Goldie (2011) maintains that "empathetic perspective-shifting", where one comes to somehow adopt the subjective perspective of another person, is more generally unachievable. To do this, one would have to take on the person's various psychological dispositions. However, many character traits, moods, and the like play the phenomenological roles that they do in virtue of their not being explicit objects of attention. Goldie therefore argues that one could not feed them into an explicit simulation without distorting them in the process: "B's full-blooded agency, including his characterization, becomes merely another empirical fact for A to take into account in her imaginative project" (Goldie, 2011, p.309). For similar reasons, Slaby (2014) maintains that simulation theories of empathy presuppose an overly atomistic conception of experience; one cannot replicate the more enveloping, background structure of experience. Margulies (1989, p.34) also remarks that localized experiences presuppose the "totality of the person" and must be understood in relation to it.

Even if such objections can be resisted, there is a more specific and compelling objection to be made in cases of severe psychiatric illness. Suppose one seeks to empathize with an experience that itself centrally involves a diminishment or absence of empathic ability (where empathic ability is understood in a maximally permissive way, as an ability to understand, to varying degrees, another person's experience). One could not replicate the experience without also replicating the absence of empathy: A would replicate B's lack of receptiveness to others' experience and would then be unable to attribute it to B, due to that same lack of receptiveness. A partial replication, which did not incorporate the lack of empathy, would be ineffective in all those instances where B's lack of empathy is inextricable from and central to wider-ranging 
changes in B's relationship with the social world. Neither is it plausible to maintain that A first replicates B's experience and later draws on the memory of doing so in order to empathize with A, where remembering one's lack of empathy does not involve a continuing inability to empathize. This would imply that A ultimately comes to grasp B's experience via something that is not a simulation of B's experience, thus raising the question of why a simulation is needed in the first place. If empathy depends proximally on $x$, which is not a simulation of experience, the simulationist needs an account of how $x$ itself depends upon something that is a simulation.

I think it is more plausible to maintain that empathy, in the kinds of case I am concerned with, involves acknowledging an enduring phenomenological distance between two parties, rather than traversing that distance. One could of course draw upon memories and exercises of imagination in order to aid the task of understanding, but not in a way that closes this gap. I should add that the point applies not only to 'empathic perspective-shifting' but also to the less ambitious goal of 'putting oneself in her shoes'. When one asks 'what would I do in her shoes?', the shoes in question are partly comprised of a profoundly different way of experiencing and relating to the world. B either recognizes that she cannot accomplish this, or she is mistaken when she thinks the desired result has been achieved. Of course, one could maintain that empathy is outright impossible in these cases. Hence, as we never manage to empathize with experiences that themselves involve a lack of empathy, there is no problem for the simulationist to address. In response, we need only note that when empathy is recognized as arising in these situations (and it frequently is), the term must be referring to something other than simulation, and it is this achievement that I seek to further clarify here.

\section{Three Kinds of Second-Person Experience}

It might be objected that I have so far offered an overly negative conception of empathy. It involves only the recognition of difference, whereas empathy is more usually construed in terms of experiencing something of what the other person experiences. It thus involves a more positive understanding of someone else's mental life, as well as something more specific than understanding (where the term 'understanding' is used in a general, noncommittal way): experiencing. This, one might add, is surely still to be construed in terms of simulation. Even if explicit simulation can rightly be said to involve "experiencing something of what someone else 
experiences', I have already ruled that out. However, it is not the only sense in which one might be said to do so, and I will conclude by considering three other candidates.

In the phenomenological tradition of philosophy, empathy has been construed not as a matter of simulation but as a distinctive, sui generis type of intentional state, which has another person's experience as its object. Just as I might perceive an object or believe a proposition to be true, I empathize with the experiences of others. This involves a perception-like apprehension of a person's experience, which is manifest in her perceived expressions, gestures, movements, and tone (e.g. Stein, 1817/1989; Zahavi, 2007, 2011, 2014, Thompson, 2007). The claim that empathy involves a distinctive way of relating to another person is compatible with what I have so far said. One directs one's attention towards her, in a way that involves a distinctive degree and kind of openness to specifically interpersonal forms of difference. Empathy can thus be construed in terms of a certain type of second-person relation. However, the claim that this relation gives one some degree of access to another person's experience is more specific and contentious. The extent of this access is also unclear: can you experience that someone else is happy, that they are happy about $p$, or even that they are happy about $p$ because of $x$ ? Given this emphasis on a perceptual or perception-like experience, it has been objected that this view is in fact compatible with an implicit simulationist account of empathy. In short, the perceptual or quasi-perceptual grasp of second-person experience that certain phenomenologists describe could be reliant upon the operation of implicit simulation mechanisms (e.g. Currie, 2011). However, others have disputed this, maintaining that the perception of second-person experience does not involve simulation (e.g. Gallagher 2007).

I allow, for the sake of argument, that empathizing with psychiatric illness can involve a fairly superficial, perception-like appreciation of what another person experience. I also allow that this may turn out to be somehow reliant on implicit simulation processes (which are to be distinguished from the kinds of explicit simulation that have been my main concern up to this point). However, it needs to be added that this operates in conjunction with an importantly different kind of 'second-person experience'. When interacting with someone who is profoundly socially isolated, a more usually harmonious interplay of word, expression, gesture, and action breaks down to varying degrees. Interactions become awkward and uncomfortable, and the other 
person's experiences no longer appear embodied in her expressions, gestures, and tones in an unambiguous, unproblematic way. Consider, for instance, the so-called 'praecox feeling', which is said to characterize interactions with schizophrenia patients (no doubt only some people's interactions with some people who have that diagnosis). This involves a general feeling of unease and lack of interpersonal connection that can serve as a fairly reliable guide for diagnosis (see Varga, 2013, for a discussion). Peter Hobson (2002, p.49) describes having a similar kind of experience when interacting with autistic people: "A person can feel that there is something missing when relating to someone who is autistic - it is as if one is in the presence of a changeling, someone from a different world - but this escapes the net of scientific methods".

Now, if empathy is construed as a quasi-perceptual appreciation of experience (something that operates most effectively in the context of harmonious interactions between people), we can simply construe these experiences in terms of a breakdown of empathy. On the other hand, such breakdowns can make a positive contribution to the kind of empathy that I am addressing. It would be an oversimplification to state that, even if explicit simulation is ineffective when we seek to understand radically different forms of experience, implicit simulation persists. In fact, it is the disruption of a quasi-perceptual process (a process that may or may not be legitimately construed in terms of implicit simulation) that should be emphasized. The experience of disruption is at the same time a way of experiencing the other person. Insofar as one's interaction with her is out of synch or otherwise lacking, she may appear strange, somehow different. Hence the distance between one's own world and hers is something that can, to some extent at least, be experienced. This is a prominent theme in the work of Minkowski (1933/1970, Part II, Chapter 1), who invites the clinician to reflect upon how she feels when interacting with a patient, upon "the feeling we have in the presence of certain patients when we attempt to grasp their living personality" (pp.223-4). Such feelings, he suggests, are double-sided: how one feels is also a way of experiencing the other person. They can therefore feed into the empathic project, helping one to grasp the nature of the difference and, ultimately, to achieve a positive characterization. One can come to better understand the person by spending a prolonged period of time with him, interacting with him, and attending to one's feelings: 
It was like two melodies being played simultaneously, although these two melodies are as dissonant as can be, a certain balance becomes established between the notes of one and the other and lets us penetrate a little further into our patient's psyche. (Minkowski, 1933/1970, p.182)

So the person is understood, not through the kind of experience allegedly enabled by implicit simulation routines but through its disruption. However, it might still be objected that all of this provides us with an inadequate grasp of what the other person does experience. A sense of difference, regardless of whether or not it is experienced, does not add up to a positive empathic understanding. And perhaps, one might reiterate, it is only through one or another kind of simulation that this can be achieved. However, I think there is a third way in which one can rightly be said to 'experience someone else's experience' in this context, something that can involve a positive phenomenological appreciation of profoundly different 'worlds'. In short, one can elaborate on the initial experience of difference by means of narrative. An obvious objection to this proposal is that narrative cannot contribute to one's experience of someone else's world; narrative supplies us instead with a supplementary, non-phenomenological appreciation. But there are reasons to resist that view. Consider gazing at a work of art while someone explains to you the circumstances in which it arose, the intentions of the artist, the artistic techniques employed, what makes it unique and important, how it is best viewed, and so forth. In cases like this, one's attention may remain directed at the piece, rather than distracted by the narrative. At the same time, experience of the piece is altered and enriched. One comes to see it differently and more discerningly; it looks different. It is debatable whether this kind of enriched experience is properly regarded as 'perceptual'. But the only point I want to insist on is that, phenomenologically speaking, one's immediate experience of the piece is shaped by the narrative that one acquires. It is not that the experience remains wholly insulated from the influence of a body of propositional knowledge.

I think something analogous to this occurs in the case of second-person experience. One's attention remains directed at the other person and her experiences, rather than turned inwards towards one's own mental life. However, an increasingly elaborate and nuanced narrative is assembled, which continually shapes and re-shapes what one experiences of the other person's world. This is especially so when there is some degree of cooperation between the two parties. 
As Gallagher (2012, p.370) suggests more generally, empathy is not a matter of replicating other people's experiences so much as situating those experiences in a wider context of meanings, "getting to know their stories". Furthermore, it is arguable that narrative and experience, especially emotional experience, are inextricable, that some or all emotions are partly constituted by narrative structure and content (Goldie, 2012). Hence, insofar as a narrative is shared by two parties, it comprises a kind of bridge between them that aids interpretation. Recognition of difference is thus embellished with a positive phenomenological appreciation of experience, something that does not require 'having the same experience as the other person' in a first-person way.

This is not to suggest that first- and second-person narratives will always be congruent or that interpretations will ever fully converge. Even if it is admitted that narrative and experience cannot be cleanly separated, there remains the possibility of outright misinterpretation (on the part of one or both parties) and self-deceit. It can be added that A's interpretation of B's experience may involve insights into its nature that B lacks, opening up the possibility of B's reinterpreting and reshaping her experience by engaging with A's narrative (e.g. Margulies, 1989). First-person narratives may also be fragmented or lacking in some respect, something that can itself be revealing and contribute to empathic interpretation. And the relationship goes both ways. A's interaction with B is also self-affecting, serving to reshape her own experience to varying degrees and in different ways. So the difference between first- and second-person perspectives on experience is preserved throughout. The end result is not a final, fixed narrative, given that the relationship between experience and self-interpretation is a dynamic and openended one. These points complement another prominent theme in the clinical literature: that empathy generally takes the form of a variably cooperative interpersonal process of whatever duration, rather than an episodic achievement by a single individual. As Coulehan et al. (2001, p.222) suggest, empathy "allows the patient to feel understood, respected, and validated", thus facilitating a kind of "feedback loop" through which her experience is progressively clarified. This process not only enables one to appreciate another person's experience; it also shapes and re-shapes the experiences of both parties as it progresses (Havens, 1986, p.21; Margulies, 1989, p.97). 
We therefore arrive at an account of what it is to empathize with profound phenomenological changes that arise in psychiatric illness (and, no doubt, in various other circumstances as well). It minimally involves a distinctive kind of openness to another person's experience. In addition, it may involve the narration of experience, something that can be achieved through an interpersonal process, involving differing degrees of cooperation or lack thereof. I do not wish to deny that a narrative, empathic appreciation of very different forms of experience can be accomplished in other ways as well, such as interpreting texts and other sources. However, as Jaspers remarks, interpersonal interactions generally yield greater insight:

The most vital part of the psychopathologist's knowledge is drawn from his contact with people. What he gains from this depends upon the particular way he gives himself and as therapist partakes in events, whether he illuminates himself as well as his patients. The process is not only one of simple observation, like reading off a measurement, but the exercise of a self-involving vision in which the psyche is glimpsed. (1913/1963, p.21)

This 'giving', I suggest, is to be construed in terms of a distinctive way of relating to another person, one that involves an unusual degree of sensitivity to the possibility of phenomenological difference, and the 'self-involving vision' in terms of an interpersonal process that empathic openness facilitates. From here, we can go on to address the questions of how widely applicable this conception of empathy might be, whether there are there are also other, quite different kinds of empathy, and whether certain philosophical approaches to empathy sometimes refer to the kind of achievement I have described here, but inadvertently mischaracterize it.

Acknowledgements: Thanks to Heidi Maibom for reading and offering helpful comments on an earlier version of this chapter.

\section{References}

Berg, J.H. van den. 1972. A Different Existence: Principles of Phenomenological Psychopathology. Pittsburgh: Duquesne University Press.

Coplan, A. 2011. Will the Real Empathy Stand Up? A Case for a Narrow Conceptualization. The Southern Journal of Philosophy 49, Spindel Supplement: 40-65. 
Coulehan, J.L., Platt, F.W., Egener, B., Frankel, R., Lin, C-T, Lown, B and Salazar, W.H. 2001. 'Let Me See if I Have This Right...' Words that Help Build Empathy. Annals of Internal Medicine 135: 221-227. Currie, G. 2011. Empathy for Objects. In Coplan, A. and Goldie, P. eds. Empathy: Philosophical and Psychological Perspectives. Oxford: Oxford University Press: 82-95.

Darwall, S. 1998. Empathy, Sympathy, Care. Philosophical Studies 89: 261-282.

Gallagher, S. 2007. Simulation Trouble. Social Neuroscience 2: 353-365.

Gallagher, S. 2012. Empathy, Simulation and Narrative. Science in Context 25: 355-381.

Goldie, P. 2011. Anti-Empathy. In Coplan, A. and Goldie, P. eds. Empathy: Philosophical and Psychological Perspectives. Oxford: Oxford University Press: 302-317.

Goldie, P. 2012. The Mess Inside: Narrative, Emotion, and the Mind. Oxford: Oxford University Press. Goldman, A. 2006. Simulating Minds: the Philosophy, Psychology and Neuroscience of Mindreading. Oxford: Oxford University Press.

Goldman, A. 2011. Two Routes to Empathy: Insights from Cognitive Neuroscience. In Coplan, A. and Goldie, P. eds. Empathy: Philosophical and Psychological Perspectives. Oxford: Oxford University Press: $31-44$.

Gordon, R. 1995. Sympathy, Simulation, and the Impartial Spectator. Ethics 105: 727-742.

Halpern, J. 2001. From Detached Concern to Empathy. Oxford: Oxford University Press.

Halpern, J. 2003. What is Clinical Empathy? Journal of General Internal Medicine 18: 670-674.

Havens, L. 1986. Making Contact: Uses of Language in Psychotherapy. Cambridge MA: Harvard University Press.

Hobson, P. 2002. The Cradle of Thought. London: Macmillan.

Hornstein, G. 2009. Agnes's Jacket: A Psychologist's Search for the Meanings of Madness. New York: Rodale.

Jaspers, K. 1912/1968. The Phenomenological Approach in Psychopathology. British Journal of Psychiatry 114: 1313-1323.

Jaspers, K. 1913/1963. General Psychopathology. Translated from the German Seventh Edition by Hoenig, J. and Hamilton, M.W. Manchester: Manchester University Press.

Margulies, A. 1989. The Empathic Imagination. New York: W.W. Norton \& Company.

Minkowski, E. 1933/1970. Lived Time: Phenomenological and Psychopathological Studies. (Trans.

Metzel, N.) Evanston: Northwestern University Press.

Pienkos, E. and Sass, L.A. 2012. Empathy and Otherness: Humanistic and Phenomenological Approaches to Psychotherapy of Severe Mental Illness. Pragmatic Case Studies in Psychotherapy 8: 25-35.

Ratcliffe, M. 2012. Phenomenology as a Form of Empathy. Inquiry 55: 473-495. 
Ratcliffe, M. 2015. Experiences of Depression: A Study in Phenomenology. Oxford: Oxford University Press.

Sechehaye, M. ed. 1970. Autobiography of a Schizophrenic Girl. New York: Signet.

Shaw, F. 1997. Out of Me: The Story of a Postnatal Breakdown. London: Penguin.

Slaby, J. 2014. Empathy's Blind Spot. Medicine, Healthcare and Philosophy 17: 249-258.

Stein, E. 1917/1989. On the Problem of Empathy. (Trans. Stein, W.) Washington D.C.: ICS Publications.

Stueber, K.R. 2006. Rediscovering Empathy: Agency, Folk Psychology and the Human Sciences.

Cambridge MA: MIT Press.

Thompson, E. 2007. Mind in Life: Biology, Phenomenology, and the Sciences of Mind. Cambridge MA: Harvard University Press.

Varga, S. 2013. Vulnerability to Psychosis, I-Thou Intersubjectivity and the Praecox-Feeling.

Phenomenology \& the Cognitive Sciences 12: 131-143.

Zahavi, D. 2007. Expression and Empathy. In Hutto, D.D. and Ratcliffe, M. eds. Folk Psychology Reassessed. Dordrecht: Springer: 25-40.

Zahavi, D. 2011. Empathy and Direct Social Perception: a Phenomenological Proposal. Review of Philosophy and Psychology 2: 541-558.

Zahavi, D. 2014. Self and Other: Exploring Subjectivity, Empathy, and Shame. Oxford: Oxford University Press. 